\title{
EDITORIAL
}

\section{Ethical Issues In Medical Practice}

Ethics is the understanding of moral values. Medical ethics means the moral principles, which should guide the members of the medical profession in the course of their practice of medicine and in relationship with their patients and other members of the profession ${ }^{\mathbf{1 , 2}}$. Recent advances in medicine and the amazing advances in technology have brought ethical issues in the forefront. WHO has given special emphasizes to work on some specific health issues like treating HIV/ AIDS patients, patients with mental illness, making end-of-life decision (Euthanasia), organ donation and transplantation, medical termination of pregnancy, creation and uses of registries and bio banks, informed consent in a vaccine field trial, cloning of species and also research of stem cells from an intact embryo ${ }^{3}$.

The history of medical ethics is since the Code of Hammurabi about 2200 BC. Then Greek physician Hippocrates declared an oath known as "Hippocratic Oath" within 460 to 377. The Hippocratic Oath was formulated in the 4th century BC. The oath became the nucleus of all medical ethics ${ }^{4}$. The oath was modified during the $20^{\text {th }}$ century, but its ethical strength remained. The modified version was written by Lasagna, which eventually became known as the Oath of Lasagna ${ }^{4}$. In 1948, the Second World Medical Assembly adopted a modern equivalent of the Hippocratic Oath. Known as the Declaration of Geneva, the declaration was amended in 1968 and again in $1983^{5}$. The modern principles of medical ethics were prepared by Thomas Percival in 1803. Lastly Geneva declaration was declared in 1948 and was accepted in 1949. American Medical Association adopted its first code of ethics, with this being based in large part upon Percival's work ${ }^{6}$.

Education in medical ethics is lacking in most countries. Unfortunately these are not practiced in most third world countries including in Bangladesh. Presently the concept of "recent advances" in medical ethics has been developed in five areas - end of life care, medical error, priority setting, biotechnology, and medical ethics education and anticipate two future issues - "e Health" and global bioethics. The main recent advance has been the General Medical Council's requirement that medical ethics be a core subject in the medical curriculum and the development of a medical ethics curriculum ${ }^{7}$ -Worldwide, many medical schools offer structured programs for teaching medical ethics to their students..

Bioethicists often refer to the four basic principles of health care ethics when evaluating the merits and difficulties of medical procedures. Ideally, for a medical practice to be considered "ethical", it must respect all four of these principles: autonomy, justice, beneficence, and non-maleficence ${ }^{8}$.

Medical Etiquette, Professional infamous conduct, Conviction,Contravention, Covering, Issuing false certificate, Dichotomy,Advertising,Professional death sentence, Professional secrecy, Negligency and Malpractice etc. are the major issuses which to be taken into consideration for ethical medical practice.

Methods for Ethical Problem Solving :

When moral values are in conflict, the result may be an ethical dilemma or crisis. There are no crystal cut set of ethical guidelines for the physicians to follow. Then how do we in our routine clinical practice manage ethical dilemmas? WHO described ethical dilemma as a dilemma between different values which are seen as important or beneficial, but which in particular cases and circumstances are in conflict with each other. In such cases a physician has to choose which value is more important or the physician may refer to add values and to consider contexts to be able to make a decision.

The American Medical Association has developed ethical guidelines and principles which 'are not laws', but standards of conduct which define the essentials of honourable behavior for the physicians. ${ }^{9}$ In making clinical decisions the 'Case based ethical reasoning model' described by Jonsen ${ }^{10}$ is a practical method for evaluating clinical ethical problems. In order to solve an ethical dilemma four basic topics must be reviewed, as these are always present in every case regardless

of the circumstances. These are: 1 . Medical indications 2. Patient preferences. 3. Quality of life 4. Contextual features, i.e., the external socioeconomic features. 
The four principles of bioethics are then utilized in solving these individually. For example, medical indications and quality of life will involve principles and rules of beneficence and normalficence. Patient preferences may deal with issues of autonomy and informed consent. Contextual features might deal with concepts of justice and fairness. One should always consider patients preferences and ask the patient if he has been adequately informed and understands about the risks and benefits. If the patient is knowledgeable and has understood everything it is his right to choose, which should be respected. In Bangladesh, the contextual features take a very important aspect of solving an ethical dilemma, as they include family issues, religious and cultural factors, legal implications and above all, the issue of economics.

In some cases ethical theories and principles do not help physicians in resolving conflicts, other approaches to clinical ethics have been suggested. ${ }^{11}$ Instead on relying on theories some writers resolve dilemmas by looking at the concrete details of a particular case. ${ }^{12}$ They believe that moral rules are not absolute; they merely create presumptions that may be rebutted depending on the particular circumstances. Proponents of case based ethics emphasize the need for what Aristotle called 'practical wisdom' i.e., the ability to make appropriate.

Medical ethics is a code of conduct for the member of the medical profession in order to render the best possible service to the humanity and to maintain the honors and dignity of the profession. The goal of medical ethics is to improve the quality of patient care by identifying, analyzing, and attempting to resolve the ethical problems that arise in the practice of clinical medicine ${ }^{\mathbf{1}}$.The revolution in information technology will dramatically change medical practice. This subject raises many ethical issues, including confidentiality of electronic medical records, and the relation of clinical records to research and management of health systems. There will also be a dramatic change in the way physicians learn and access the medical literature. To address these issues, a code of ethics for "e Health" has been developed ${ }^{7}$.

Physicians should try continuously to improve medical knowledge and skills and should make available to their patients and colleagues, the benefits of their professional attainments. The physician should practice methods of healing founded on scientific basis and should not associate professionally with anyone who violates this principle (truthfulness and honesty). The honored ideals of the medical profession imply that the responsibilities of the physician extend not only to individuals but also to society which is the demand of the present time.

Today, the formulation of medical ethics has become a multidisciplinary endeavor, often involving teams that may include clergy, philosophers, scientists, and lawyers, as well as physicians and nurses ${ }^{13}$. Medical ethics is an important part of the undergraduate medical curriculum. So, It should be practice from the first day of our medical life.

In conclusion, I would like to say that our patients and our society expect from us to understand the basic principles of bioethics, and use the many tools that are available.

(J Banagladesh Coll Phys Surg 2013; 31: 120-121)

\section{Prof. S.A.M Golam Kibria}

President, BCPS

\& Prof. of Urology, BSMMU

\section{References:}

1. Medical ethics. www.Wikipedia.org visited on 07.02.10.

2. Nandy A. Principles of Forensic Medicine, India: New Central Book Agency (P) Ltd,1996:15-6.

3. Teaching \& Application of Health Ethics inSouth East Asia: Health Ethics Teaching Guidelines for SEAR Countries 2002.

4. Yolly Eileen A. Gamutan R.N. Written in 1964by Louis Lasagna, Academic Dean of theSchool of Medicine at Tufts University .

5. Grolier International Encyclopedia. Visited on 07.02.10.

6. Percival, Thomas. Medical ethics. pp. 4957 esp. section 8 pg.52.

7. Peter A Singer, BMJ 2000; 321:282-285

8. Helsinki Declaration. World Medical Association Declaration of Helsinki: ethical principles for medical research involving human subjects. JAMA 2000; 284:3034-5.

9. Jonsen AR, Siegler M, Winslade WJ. Clinical ethics: a practical approach to ethical decisions in clinical medicine, 4th ed. New York: McGraw-Hill, 1998.

10. Pellegrino ED. The metamorphosis of medical ethics: a 30 years retrospective. JAMA 1993; 269:1158-62.

11. Quinn TC, Wawer MJ, Sewankambo N, et al. Viral load and heterosexual transmission of human immunodeficiency virus type 1. Rakai Project Study Group. N Engl J Med 2000;342:921-9.

12. Angell M. Investigators' responsibilities for human subjects in developing countries. N Eng J Med 2000;342:967-9.

13. Richard A, Dennis B, Solomon B, et al. Teaching and assessing ethics and law within medical education: a model for the UK core curriculum. Consensus statement by teachers of medical ethics and law in UK medical schools.BMJ 1998;316. 